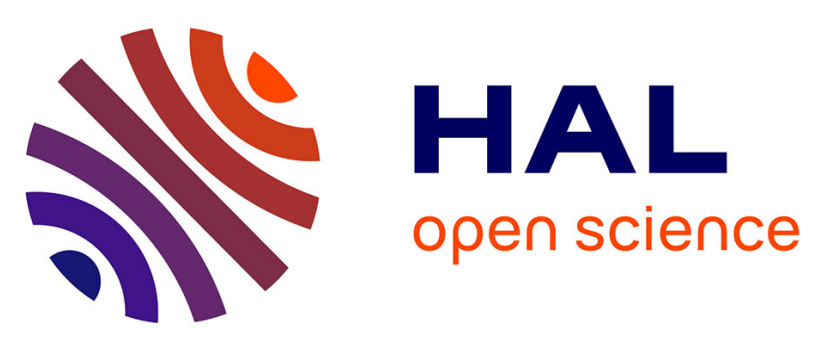

\title{
A consistent Woven Fabric Unit cell and pre-processor for meso-macro analyses of forming
} Gilles Hivet, Bertrand Laine, Philippe Boisse, Julie Chen

\section{To cite this version:}

Gilles Hivet, Bertrand Laine, Philippe Boisse, Julie Chen. A consistent Woven Fabric Unit cell and pre-processor for meso-macro analyses of forming. International Journal of Forming Processes, 2007, 10 (1), pp.109-123. hal-00299466

\section{HAL Id: hal-00299466 \\ https://hal.science/hal-00299466}

Submitted on 16 Feb 2018

HAL is a multi-disciplinary open access archive for the deposit and dissemination of scientific research documents, whether they are published or not. The documents may come from teaching and research institutions in France or abroad, or from public or private research centers.
L'archive ouverte pluridisciplinaire HAL, est destinée au dépôt et à la diffusion de documents scientifiques de niveau recherche, publiés ou non, émanant des établissements d'enseignement et de recherche français ou étrangers, des laboratoires publics ou privés. 


\title{
A Consistent Woven Fabric Unit Cell and Preprocessor for Meso-macro Analyses of Forming
}

\section{Gilles Hivet* - Bertrand Laine** — Philippe Boisse*** Julie Chen****}

\author{
* LMSP, UMR CNRS ENSAM-Polytech'Orléans \\ 8, rue Léonard de Vinci, F-45072 Orléans Cedex \\ ** ONERA
}

29 avenue de la Division Leclerc

F-92322 Châtillon

*** LMCS, UMR CNRS 5514, INSA de Lyon, Bâtiment Jean d'Alembert 18-20, rue des Sciences, F-69621 Villeurbanne cedex

**** University of Massachusetts Lowell, Department of Mechanical Engineering Advanced Composite Materials and Textile Research Laboratory

One University Ave. Lowell, MA 01854,USA

gilles.hivet@univ-orleans.fr; bertrand.laine@onera.fr

philippe.boisse@insa-lyon.fr,Julie_Chen@uml.edu

\begin{abstract}
Simulation is a powerful tool to optimize composites materials forming. Both dry fabric forming and resin flow can be simulated using fabric unit cell models. With the aim of performing analyses of the mechanical behaviour at the mesoscopic scale, an accurate geometrical model of the fabric unit cell has to be defined and meshed. Defining the geometry on which this meshing is applied is a difficult and important point. In order to determine yarn geometry for different cases of yarn structure and weave patterns, experimental observations using different optical processes have been performed. The analysis of these results helps us define an accurate 3D model of the woven yarn shape. Using this yarn model, a consistent 3D geometrical model of fabrics is presented. This model ensures an accurate contact between yarns. It is called consistent because penetrations and spurious voids between warp and weft yarns are avoided. The yarn section shape varies along the trajectory, so that the influence of contact between yarns on their cross-section shape can be taken into account. A meshing preprocessor based on this geometrical model is then developed. This is an important point for $3 D$ finite element simulation of fabrics, which is a powerful method to investigate mechanical behaviour. A consistent geometry of the fabric at the deformed state can also be obtained and used to define the influence of deformation on resin flow.
\end{abstract}

KEYWORDS: Meshing Pre-processor, Mechanical Properties, Fabric, Unit Cell, Mesoscopical Model, Geometrical Model. 


\section{Introduction}

Many processes can be used to form composite parts. For several of them (RTM for example), the first step consists in forming a dry fabric before the resin is injected (Carronnier et al., 1996; Rudd et al., 1997). Mechanical properties of the final part and its ability to be formed depends of mechanical and permeability properties of the dry fabric. Simulation of these processes is a very interesting tool in order to predict whether a composite part is obtainable without using expensive prototypes. Nevertheless, to perform simulations, fabric mechanical properties have to be known. Experimental analyses may allow the obtaining of both mechanical properties and permeability (Prodromou et al., 1997; Buet et al., 2001; Cao et al., 2004; Hoes et al., 2004). The drawback is that experiments are often expensive, time consuming and moreover don't enable to obtain results on non-existing fabrics. Thus, simulation is a good alternative to obtain fabric properties. Since most of the fabrics are periodic material, it is possible to define an elementary cell from which the fabric can be constructed. The fabric behaviour is then deduced from the elementary cell. Among the numerical approaches that aim to study elementary cell properties, finite element analysis is an efficient method, but it needs an accurate meshing of the unit cell (Boisse et al., 2001). The multi-scale nature of the fabric (macro-scale), composed of yarns (meso-scale), themselves composed of fibres (micro-scale) leads to a complicated geometry that is difficult to model. A simplified geometrical model has to be used to obtain the mesh of the elementary cell. Numerous models exist (Peirce, 1937; Kawabata et al., 1973; Kuhn et al., 1999; Bulusu et al., 2000; Lomov et al., 2000; Robitaille et al., 2003). Nevertheless, meshes obtained with these models are not really well adapted to finite element analysis of the unit cell since they are designed for other applications. Contact surfaces between yarns are not described precisely enough. Interpenetration between yarns, likewise the existence of unreal voids (due to the modelling) significantly affects finite element results. The goal of this study is to present a tool for the definition of a consistent 3D geometrical model of fabric and its application to a meshing pre-processor. This mesh can then be applied to finite element simulations of fabric deformation. Another application is injection simulation.

\section{Mesoscopic geometrical models}

Mesoscopic geometrical models have been developed to be able to give a better description of fabric geometry at the initial state. This geometry will be possibly strained within finite element analyses. Yarns are supposed to be continuous solids (with specific properties) and the fabric is constituted by the interlacement of these solids. The main assumption used for many of them is that the yarn section remains constant along the curvilinear trajectory. The curvilinear trajectory can be composed of sinusoids, splines, circles, or polynomials with elliptic section (Kuhn et al., 1999; Bulusu et al., 2000; Lomov et al., 2000; Robitaille et al., 2003). Some of these 
models have been applied in simulation of bi-axial behavior. Results can be found in literature (Durville, 2002; Lomov et al., 2003) and consistency between results coming from different models is presented in (Lomov et al., 2003). Nevertheless, for most of those models the contact zone is not precisely described. The contact surface between yarns is brought back to a point or/and, the consistency is not always ensured accurately enough. Some interpenetration or, on the contrary, spurious voids can be noticed near the "real" contact zone between warp and weft yarns. Above all, experimental observations that will be briefly described have shown that the hypothesis of a constant section along the yarn is not sufficient to model fabric geometry.

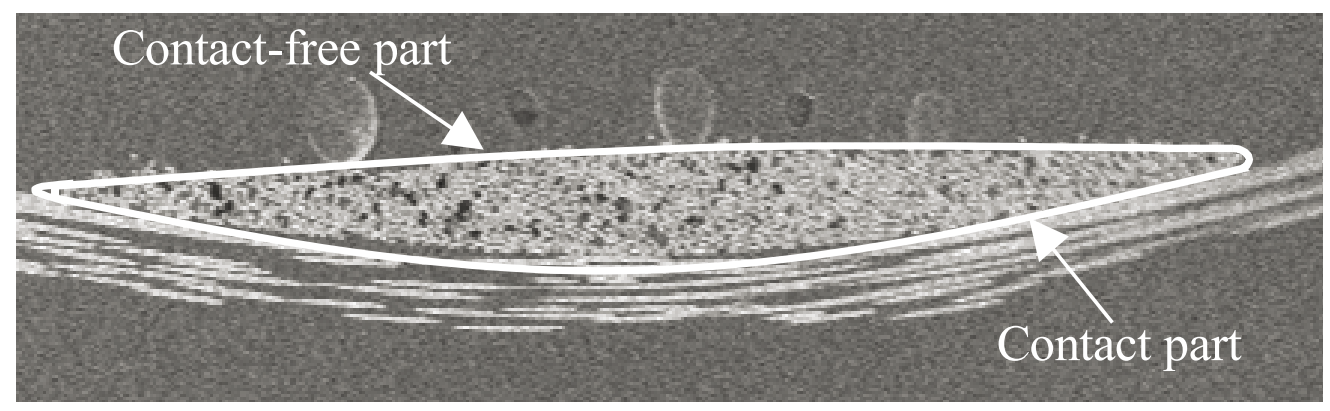

Figure 1. Transverse cut of a coated glass plain weave; definition of yarn section model

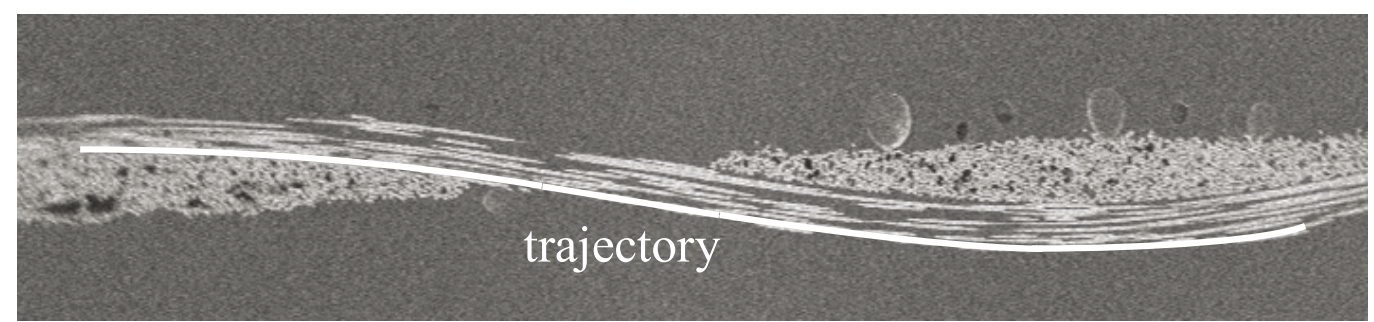

Figure 2. Transverse cut of a coated glass plain weave; definition of the trajectory model

The model developed by Kuhn and Charalambides does not have the previous drawbacks. The section varies along the trajectory, taking into account reorganization of fibers near the contact (Kuhn et al., 1999). Moreover, consistency seems to be well ensured. But this model is, to our knowledge, limited to plain weaves and has only been used to generate elementary cells of composite materials (with hard matrix). The conclusion of this preliminary study is that it is necessary to create a realistic consistent $3 \mathrm{D}$ geometrical model i.e. a geometrical model that will ensure a description of the contact zone that avoids penetrations and spurious voids (we speak of a consistent geometrical model). Existing models seem to be too geometrically constrained to be fully consistent with experimental observations for all types of weaving. 
The proposed geometrical model for fabrics is based on different experimental observations, the goal of which is

- to model accurately the contact zone between yarns,

- to ensure a consistent contact surface,

- to take the diversity of fabric geometries into account.

Yarn geometrical model is defined by the volume generated by the sweep of a section along a trajectory. Section is defined by the envelope of yarn cross section (Figure 1). Trajectory is defined by the longitudinal section of the yarn (Figure 2). The 3D model of the fabric is constituted by the consistent assembly (no interpenetration) of these yarns.

\section{Experimental observations}

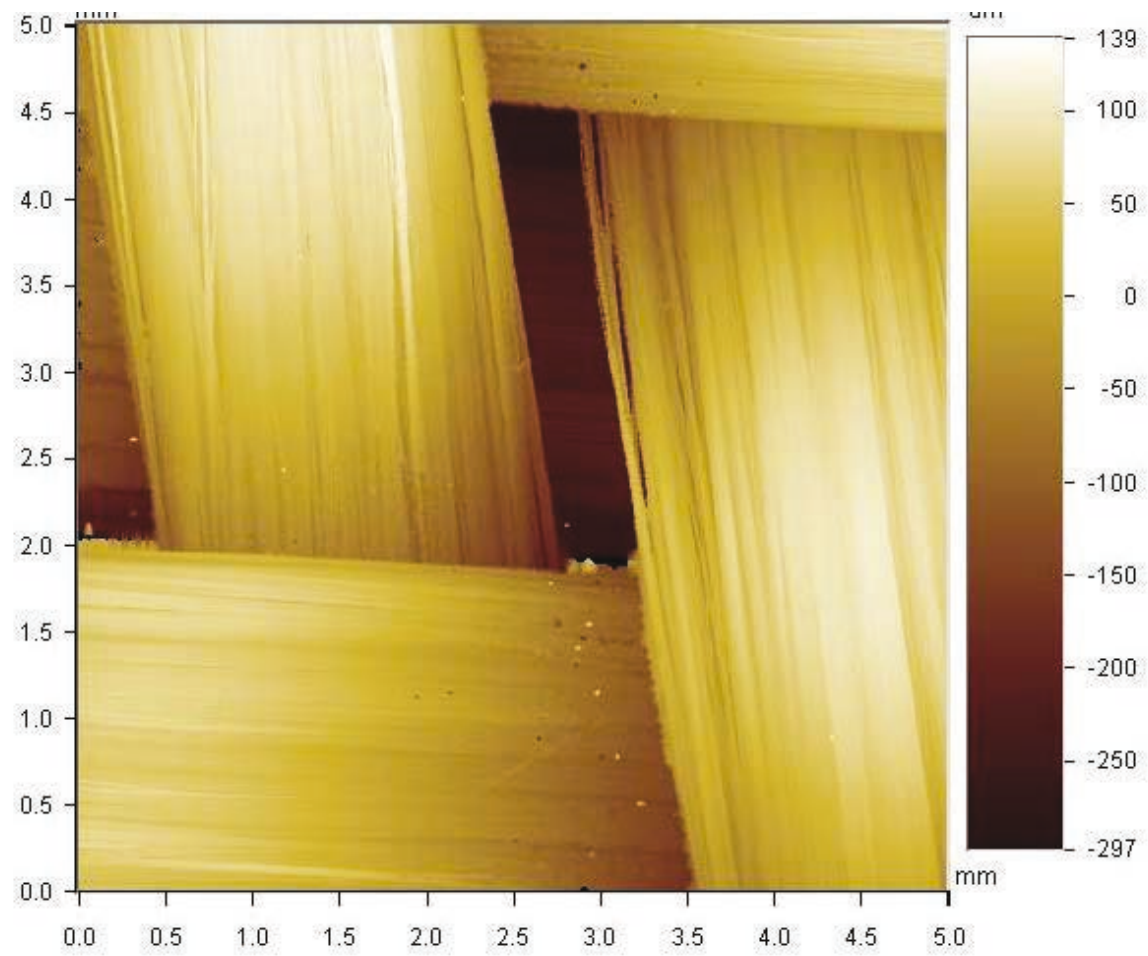

Figure 3. External view of a dry carbon twill with a white light interferometer

Different methods can be theoretically used to observe the cross section and the trajectory. For many fabrics, the cohesion between fibers is not sufficient to ensure the conservation of the cross section with contact. Thus, contact methods are not useable to identify dry fabrics geometry. Other methods must be considered to measure yarn geometry. Two other types of methods can be carried out. The first one is based on optical measures. These techniques enable to perform precise 3D geometrical measurements but only the visible parts can be obtained. The second one consists in coating a dry fabric sample with a resin to keep the original shape and then cut the sample. The resin penetratation inside the yarn, between the fibers, can modify its shape, and must be avoid as much as possible. None of these 
techniques is perfect but allowed us to obtain interesting information on the yarn section shape for a dry fabric at the initial state. Different materials and different interlacements have been observed by different methods.

From these observations, it appears that the reorganization of the fibers is an important phenomenon. The cross section is dissymmetric due to the contact, and it changes depending on boundary conditions on the fabric (Figure 1, Figure 2 and Figure 3). Both the cross and the longitudinal sections change when a tension is applied in one direction of the fabric. The tensed yarn becomes almost straight whereas the undulation of the free transverse yarn rises. Thus, the cross section has to change along the trajectory. This aspect is not usually present in most of the proposed models. The yarn section shape strongly depends on the way the yarns have been manufactured (twisted, embedded, coated). A geometrical model of fabrics has to take this diversity into account.

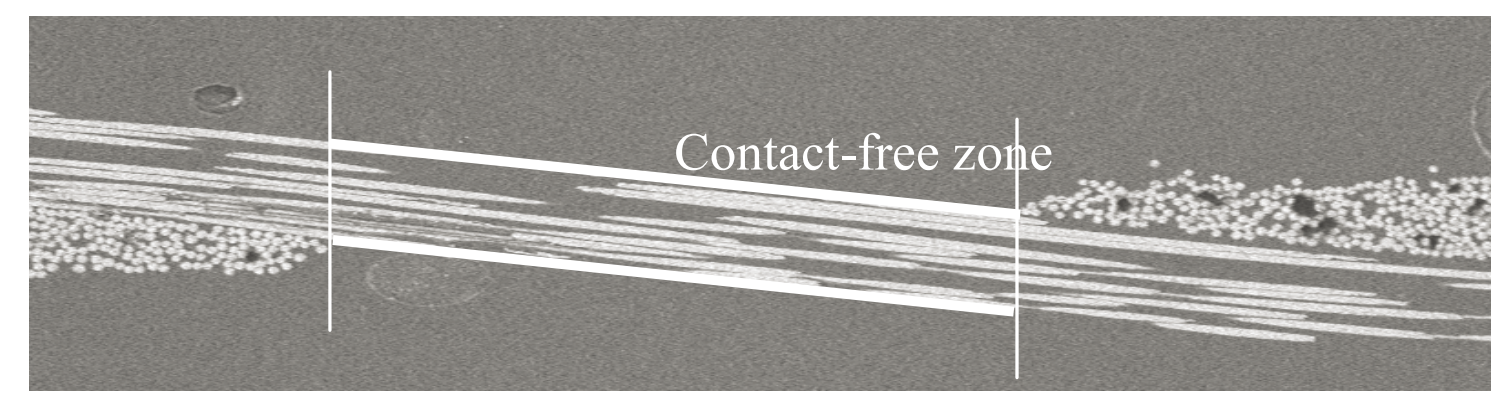

Figure 4. Transverse cut of a coated glass plain weave, contact free zone

\section{3D geometrical model}

The previous experimental observations lead us to consider three different zones for the cross section: a contact zone, a contact-free zone, and a lateral zone that can be only two points in the case of a weak cohesion of fibers (for instance figure 1). These three zones can be approached by four conic curves for instance (parabolas, circles). Values chosen for the lateral conics parameters will make them vary from straight line to dot. The trajectory is constrained by the necessary 3D consistency of the fabric model that we want to ensure. In the contact-free zone, since no lateral load is applied to the yarn and the bending rigidity of yarns is very weak, the contact-free part of the trajectory should be straight. This is confirmed by experimental observations (Figure 4). Variations of section shape along the yarn are taken into account using control sections at control points (Figure 5)(Hivet et al., 2005).

The complete 3D model of the yarn is obtained through a smooth interpolation between the control sections, which respects the imposed trajectory. The interpolation is obtained using CAD software, such as PROEngineer ${ }^{\circledR}$, which 
includes a "swept blend" feature that is able to build volumes using control sections and trajectories. The elementary cell of fabric is obtained by assembling $\mathrm{m}+\mathrm{n}$ yarns.

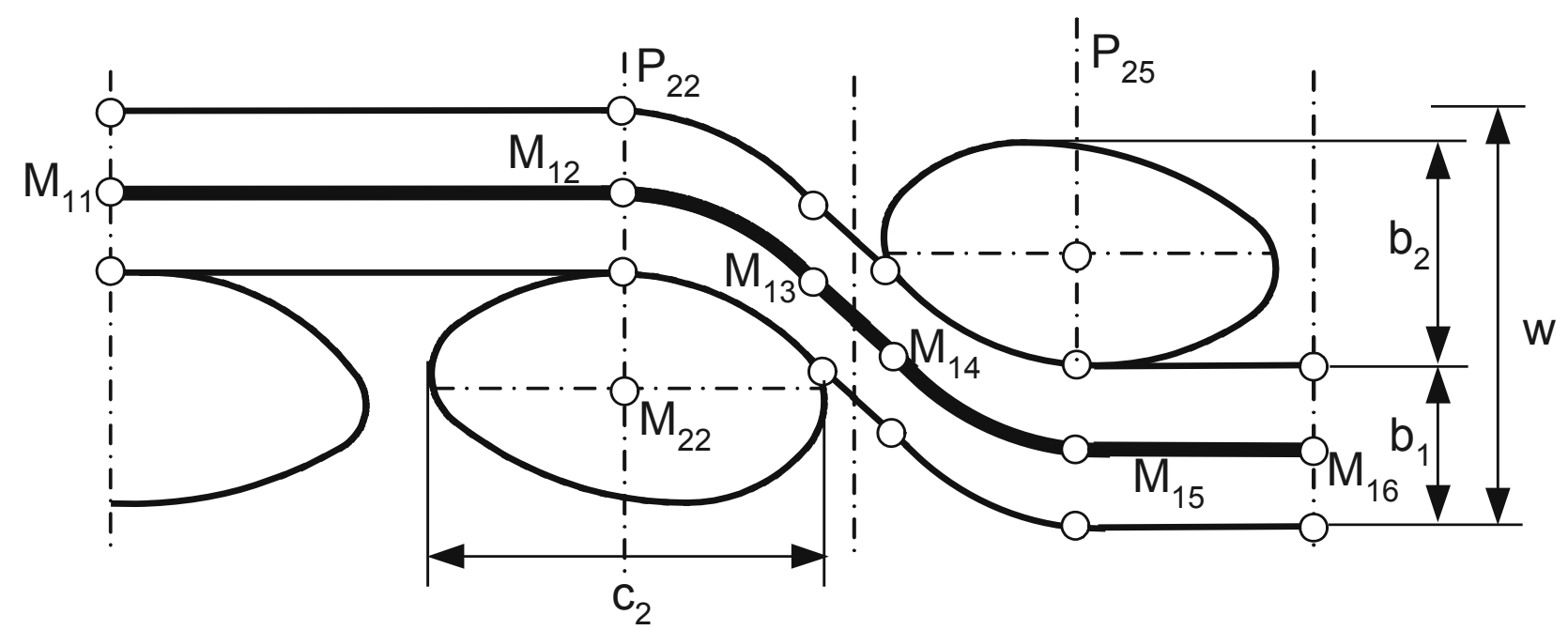

Figure 5. Transverse cut in the direction 1 of the simplified model for a twill $m^{*} n$

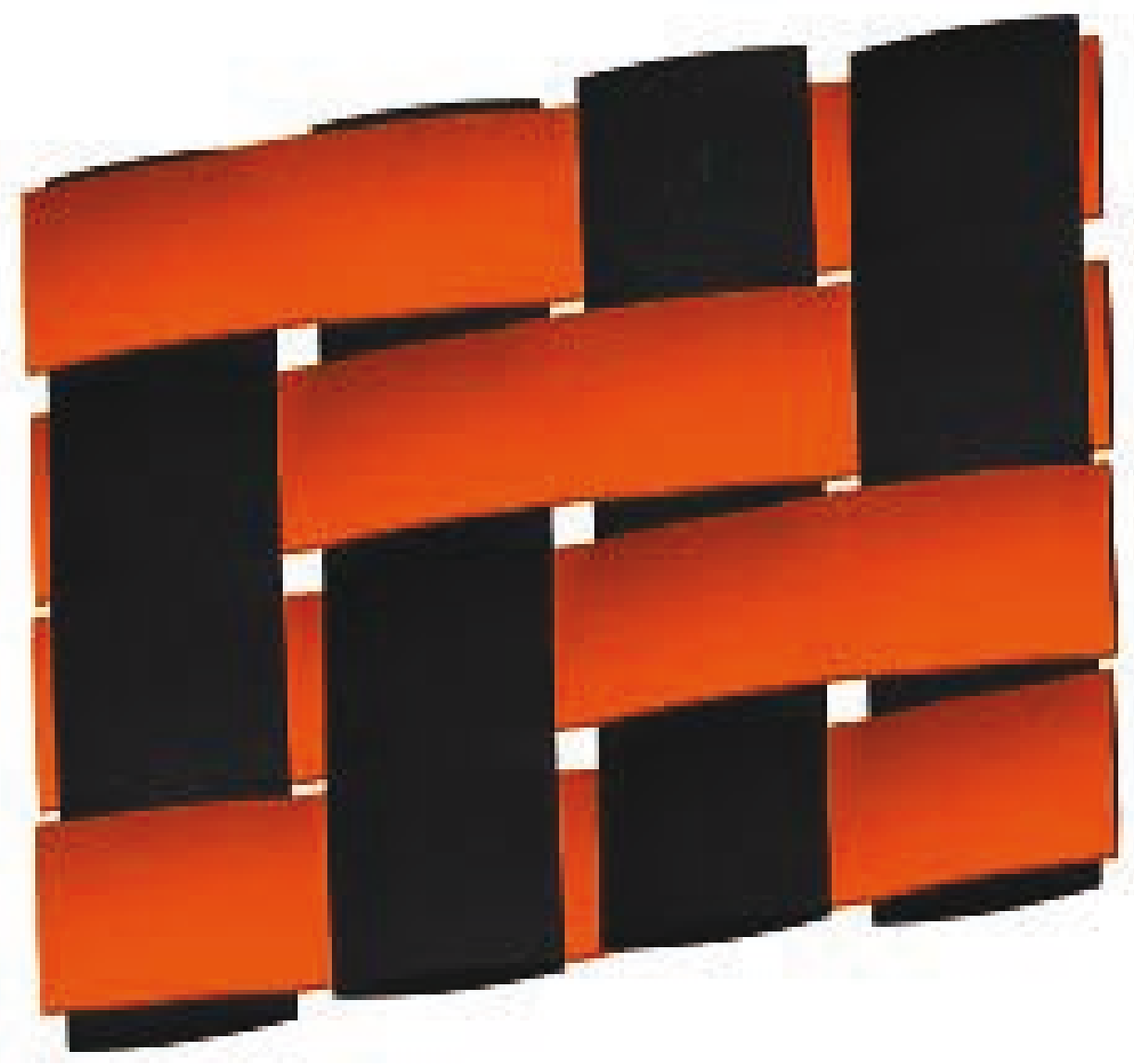

Figure 6. 3D model of a carbon twill $2 * 2$

Some examples are presented below. Figure 5 and 6 present the obtained geometry in the case of a $2 * 2$ twill, Figure 7 those of a $3 * 2$ twill and figure 8 those of a $4 * 3$ twill. Sections shapes at the beginning and the end of the contact are prescribed to ensure consistency. The model is said to be "consistent" because it 
guarantees there is no penetration between warp and weft yarns, and it imposes that contact happens where it should take. Consequently, there is no penetration and no spurious voids between warp and weft yarn. That is very important for the next computations made from the model (Figure 9).

\subsection{Parameterisation of the model}

Conics representing the contact zone are parabolas, because they have a simple parametric expression and an explicit expression for their length. The model can then be parameterized in order to be identified on a given fabric. Different types of parameterization can be defined depending on the type of fabric under consideration. The standard parameterization for a twill is presented on Figure 5.

The complete model of the elementary woven cell can be obtained from the knowledge of half a direction. Therefore, one half of the elementary cell will be studied. Conics representing the contact zone are parabolas, because they have a simple parametric expression and an explicit expression for their length. We will first the trajectory in weft direction is considered.

Control points of the trajectory are defined as $M_{\alpha i}\left(\begin{array}{c}x_{\alpha i} \\ y_{\alpha i} \\ z_{\alpha i}\end{array}\right)$ in the reference frame R. The model geometry implies that the control points are to be defined by 8 unknown coordinates:

$$
M_{11}\left(\begin{array}{l}
0 \\
0 \\
0
\end{array}\right) M_{12}\left(\begin{array}{l}
x_{12} \\
0 \\
0
\end{array}\right) M_{13}\left(\begin{array}{l}
x_{13} \\
0 \\
z_{13}
\end{array}\right) M_{14}\left(\begin{array}{l}
x_{14} \\
0 \\
z_{14}
\end{array}\right) M_{15}\left(\begin{array}{l}
x_{15} \\
0 \\
z_{15}
\end{array}\right) M_{16}\left(\begin{array}{l}
x_{16} \\
0 \\
z_{15}
\end{array}\right)
$$

Conics equations (two parabolas and two segments) are defined as:

$$
\begin{array}{ll}
\mathrm{p}_{11} & z-z_{12}=p_{11}\left(x-x_{12}\right)^{2}+q_{11} \\
\mathrm{p}_{12} & z-z_{15}=p_{12}\left(x-x_{15}\right)^{2}+q_{12} \\
\mathrm{D}_{11} & z=0 \\
\mathrm{D}_{12} & z=d_{12} x+\delta_{12} \\
\mathrm{D}_{13} & z=z_{16}
\end{array}
$$

Parameters of the curves are depending on the control points coordinates: 


$$
\begin{aligned}
& \mathrm{p}_{11}=\frac{\mathrm{z}_{13}-\mathrm{z}_{12}}{\left(\mathrm{x}_{13}-\mathrm{x}_{12}\right)^{2}}, \quad q_{11}=0, \quad \mathrm{p}_{12}=\frac{\mathrm{z}_{14}-\mathrm{z}_{15}}{\left(\mathrm{x}_{15}-\mathrm{x}_{14}\right)^{2}}, q_{12}=0, \\
& \mathrm{~d}_{12}=\frac{\mathrm{z}_{14}-\mathrm{z}_{13}}{\mathrm{x}_{14}-\mathrm{x}_{13}}, \quad \delta_{12}=\mathrm{z}_{14}-\frac{\mathrm{z}_{14}-\mathrm{z}_{13}}{\mathrm{x}_{14}-\mathrm{x}_{13}} \mathrm{x}_{14}
\end{aligned}
$$

The model is completely defined by control point. Two tangency conditions exist between segments and parabolas:

$$
\begin{aligned}
& 2 p_{11}\left(x_{13}-x_{12}\right)=2 \frac{z_{13}-z_{12}}{x_{13}-x_{12}}=\frac{z_{14}-z_{13}}{x_{14}-x_{13}} \\
& 2 p_{12}\left(x_{14}-x_{15}\right)=2 \frac{z_{14}-z_{15}}{x_{14}-x_{15}}=\frac{z_{14}-z_{13}}{x_{14}-x_{13}}
\end{aligned}
$$

8 coordinates related by two equations define the trajectory. 6 independent parameters are necessary to identify the model.

The 6 control points are defined as follows for the warp (2) direction:

$$
M_{21}\left(\begin{array}{l}
0 \\
0 \\
z_{21}
\end{array}\right) M_{22}\left(\begin{array}{l}
0 \\
y_{22} \\
z_{21}
\end{array}\right) M_{23}\left(\begin{array}{l}
0 \\
y_{23} \\
z_{23}
\end{array}\right) M_{24}\left(\begin{array}{l}
0 \\
y_{24} \\
z_{24}
\end{array}\right) M_{25}\left(\begin{array}{l}
0 \\
y_{25} \\
z_{25}
\end{array}\right) M_{26}\left(\begin{array}{l}
0 \\
y_{26} \\
z_{25}
\end{array}\right)
$$

Two tangency conditions can be written and one more relation can be established between the two trajectories to ensure the consistency of the model:

$$
z_{21}=z_{15}-z_{25} \quad z_{25}-z_{21}+z_{11}-z_{15}=2\left(z_{11}-z_{21}\right)
$$

Considering a simple geometrical model for twills that is useable for most standard fabrics, three equations can be written between the coordinates :

$$
\begin{aligned}
& x_{13}-x_{12}=x_{15}-x_{14} \\
& x_{13}-x_{12}=\frac{c_{2}}{2} \\
& z_{13}-z_{12}=z_{15}-z_{14}
\end{aligned}
$$

Most sophisticated models can be considered if a more accurate model is needed and if many parameters can be measured on the fabric. 


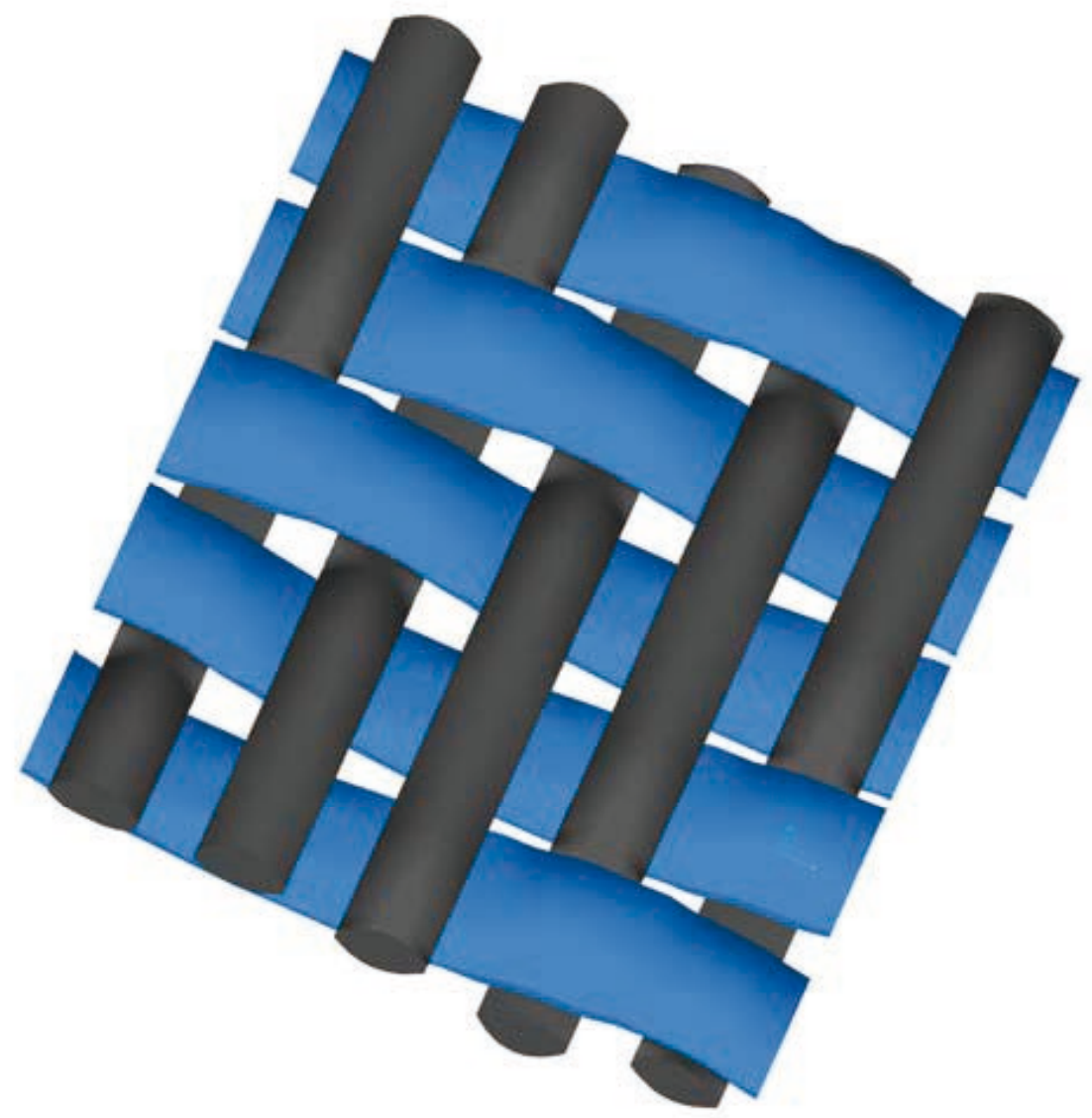

Figure 7. 3D model of a carbon twill $3 * 2$

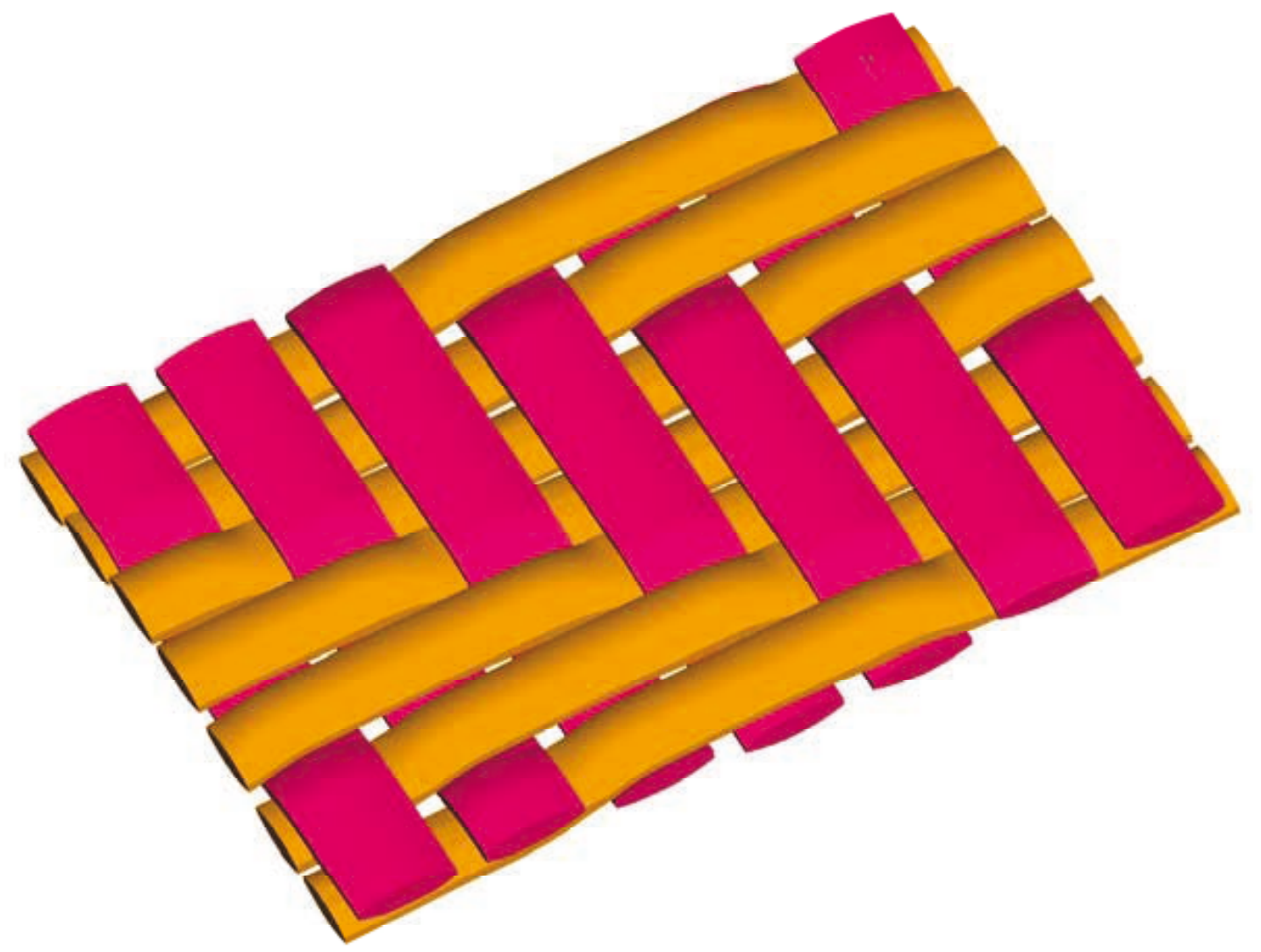

Figure 8. $3 D$ model of a carbon twill $4 * 3$ 

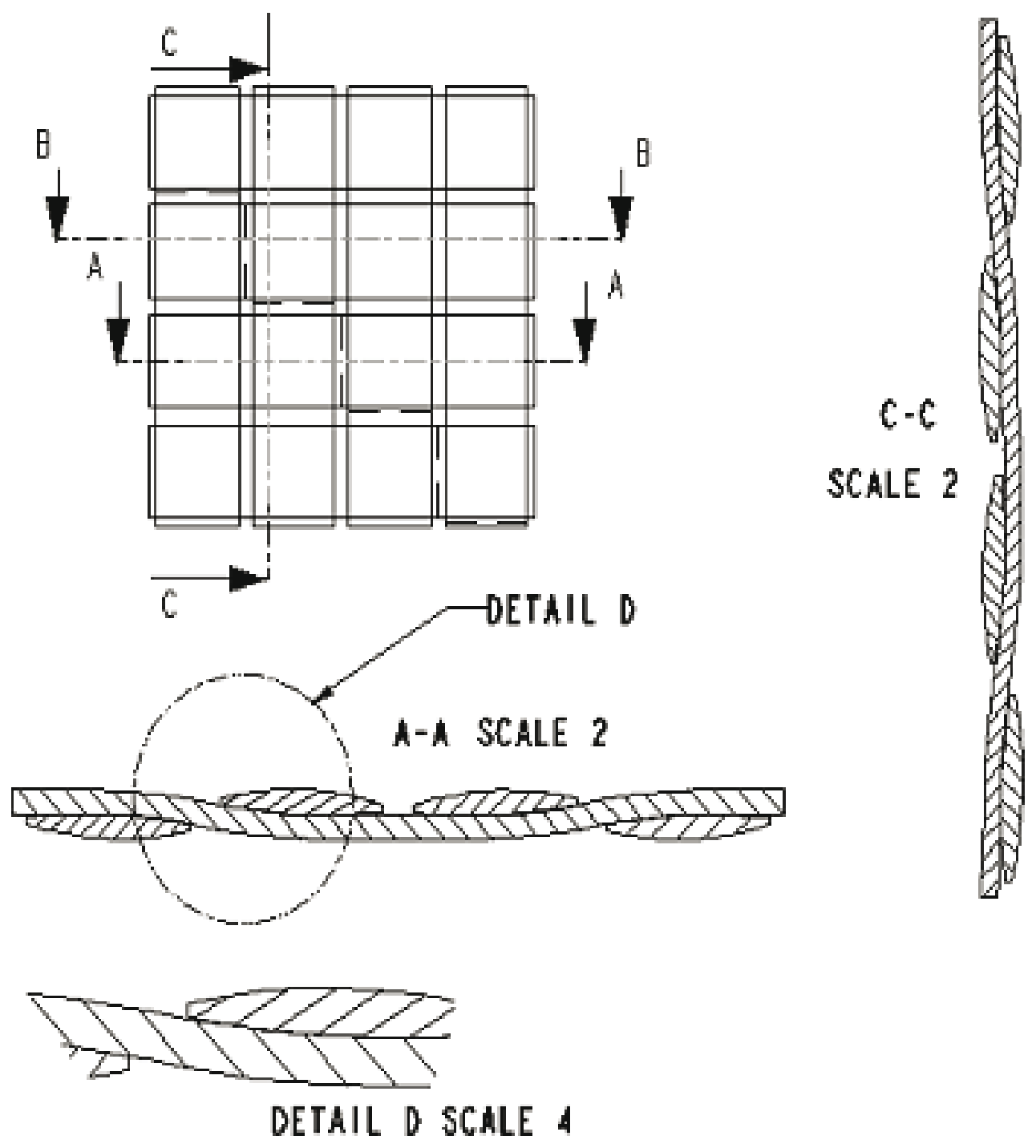

\section{B-B SCALE 2}

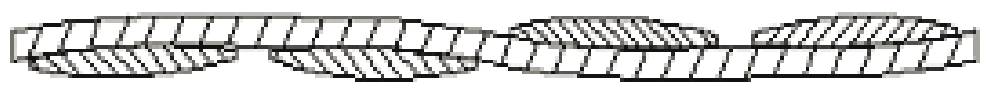

Figure 9. Transverse cut of a carbon twill $2 * 2,3 D$ model, consistency in different planes

The truss model can be identified by 6 parameters ( 3 parameters per direction) in the case of unbalanced fabrics. Considering lenticular sections, the consistency between trajectory and sections permit to build the 3D model measuring only 1 thickness (warp yarn, weft yarn or fabric) on the real fabric.

The standard complete 3D model of an unbalanced fabric may be identified by the measure of 7 parameters. These 7 parameters may be yarn width, yarn density, crimp of each direction and thickness of the fabric. For balanced fabrics only 3 parameters are needed. 
These measures are quite easy to get on fabrics, so the model will be easy to identify.

For specific fabrics and if more experimental parameters are available, more sophisticated models may be identified, using from 4 parameters per direction (i.e. 8 parameters) to 9 per direction (i.e. 18 parameters). This possibility increases the model power, because it can be adapted to the user's knowledge of the fabric, and to the degree of precision he needs. Details on the different parameterizations and on the geometrical equations can be found in (Hivet et al., 2005).

Validations of the process have been performed on five fabrics: 2 balanced plain weave, 1 unbalanced glass plain weave and 2 balanced carbon twill $2 * 2$. Two types of parameters are measured on fabrics: parameters that are necessary to identify the 3D model, and other parameters, such as fabric thickness, or yarn geometry, with the aim of comparing results given by the model against those obtained through experiments. The results obtained with the model are consistent with the real values, for instance, the ratios between measured and model thickness (for each yarn and for the fabric) for balanced, unbalanced, plain weaves and twills are less than 5\%. Many different types of fabric models have been generated, in order to confirm that any type of 2D fabrics may be modeled.

\section{Applications}

Geometries obtained using the consistent 3D model can be imported in a meshing software such as Patran ${ }^{\circledR}$. A PCL routine enables to generate automatically a hexahedral mesh of the elementary cell. In that way, a 3D geometrical meshing pre-processor of woven unit cells is defined. The mesh obtained in the case of a plain weave is presented Figure 10. These meshes permit to perform virtual tests in order to obtain the mechanical behaviour of the fabric from finite element simulations (Gasser et al., 2000). These analyses are rather easy to perform and they permit to investigate the influence of different parameters. They also allow analysing fabrics before their manufacturing. An example of the shear deformation of twill $2 * 2$ is presented figure 11 .

The 3D preprocessor is also used for the generation of the channel network geometry that is the complementary volume of the reinforcement. The obtained mesh (Figure 12) permits to simulate the resin flow (Figure 13) and to deduce the permeability matrix (Laine et al., 2005; Fournier et al., 2005). 


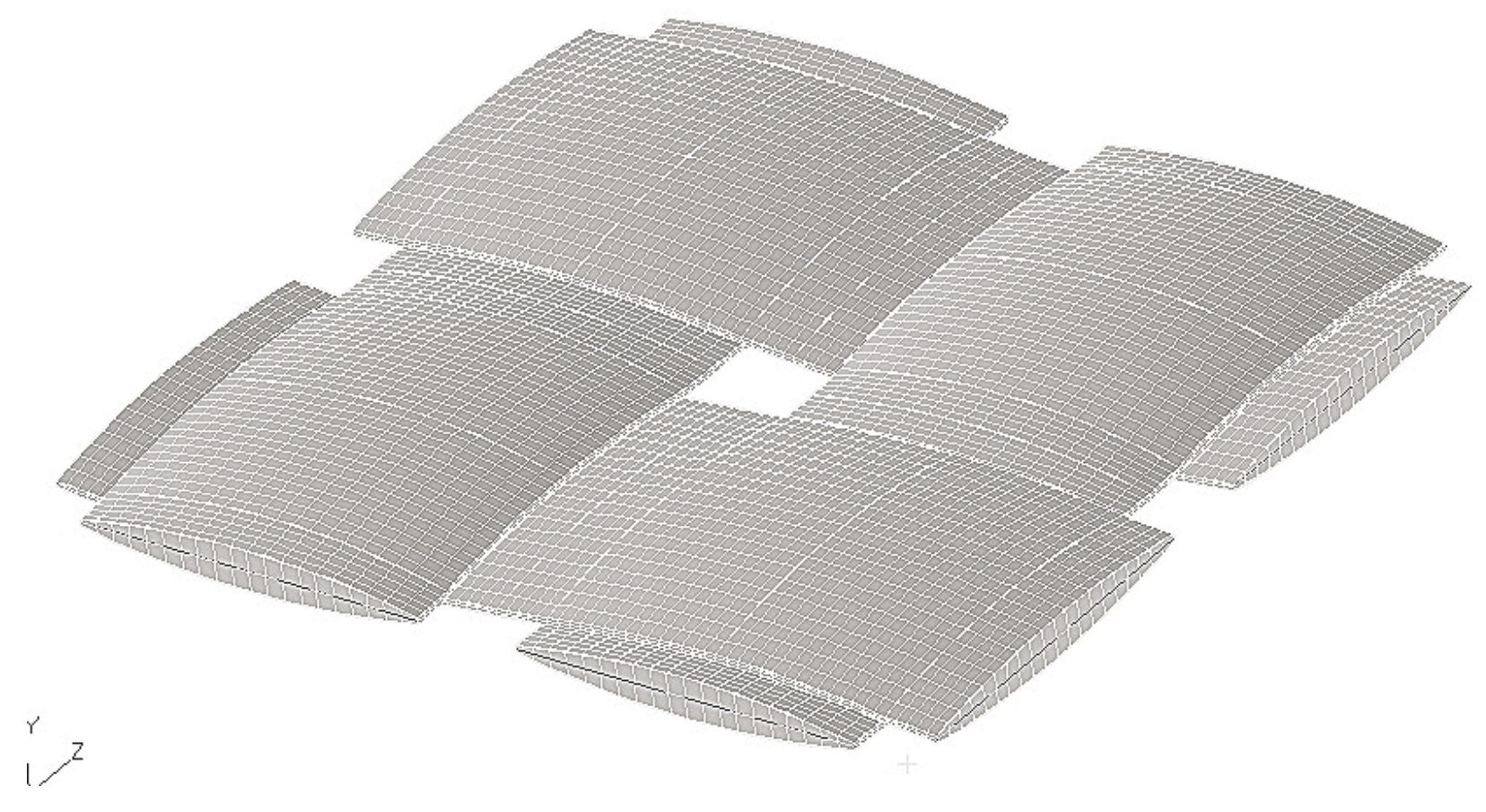

Figure 10. $3 D$ mesh for a plain weave fabric

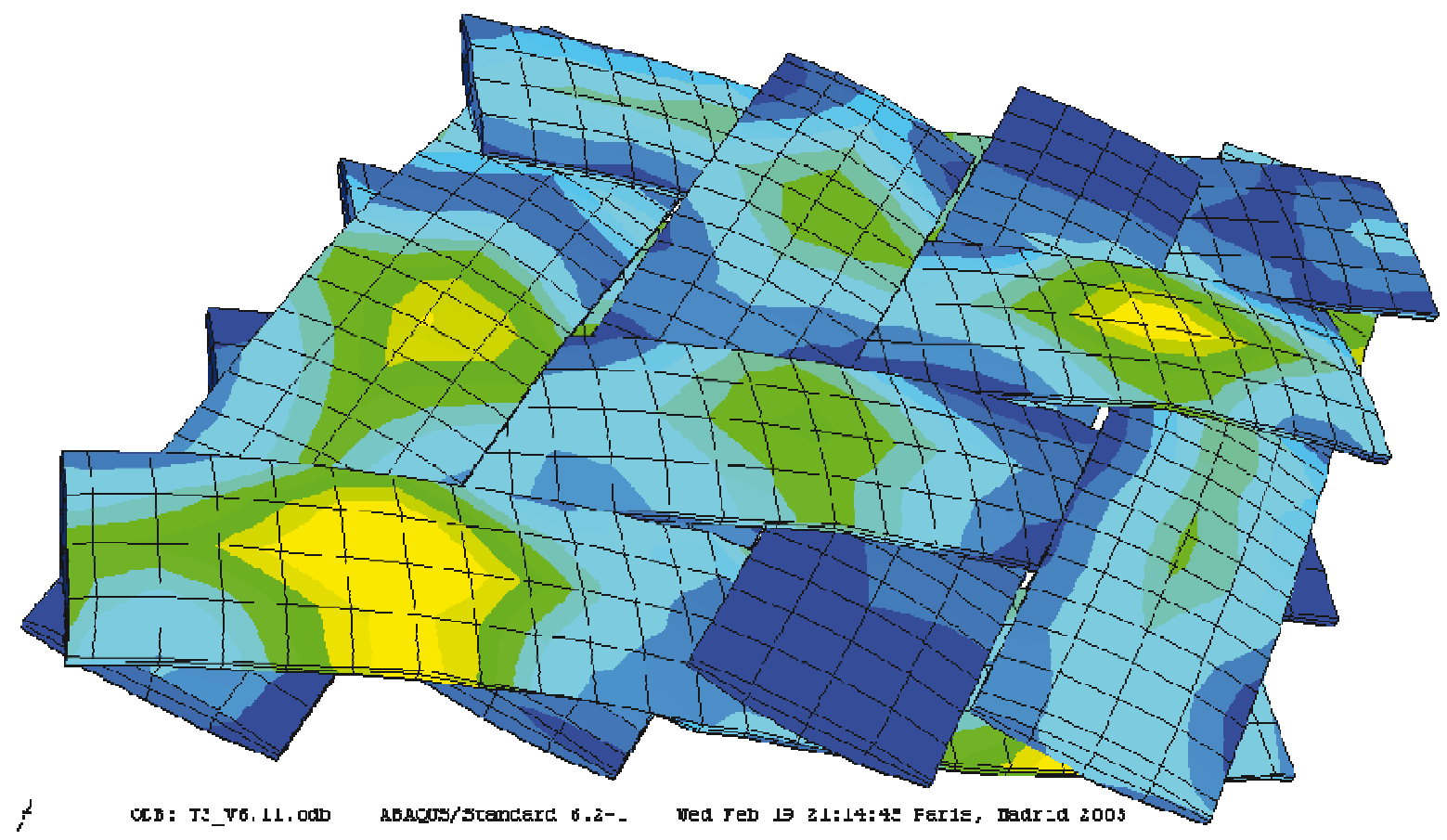

Figure 11. Finite element simulation of the shear deformation of a twill $2 * 2$ 


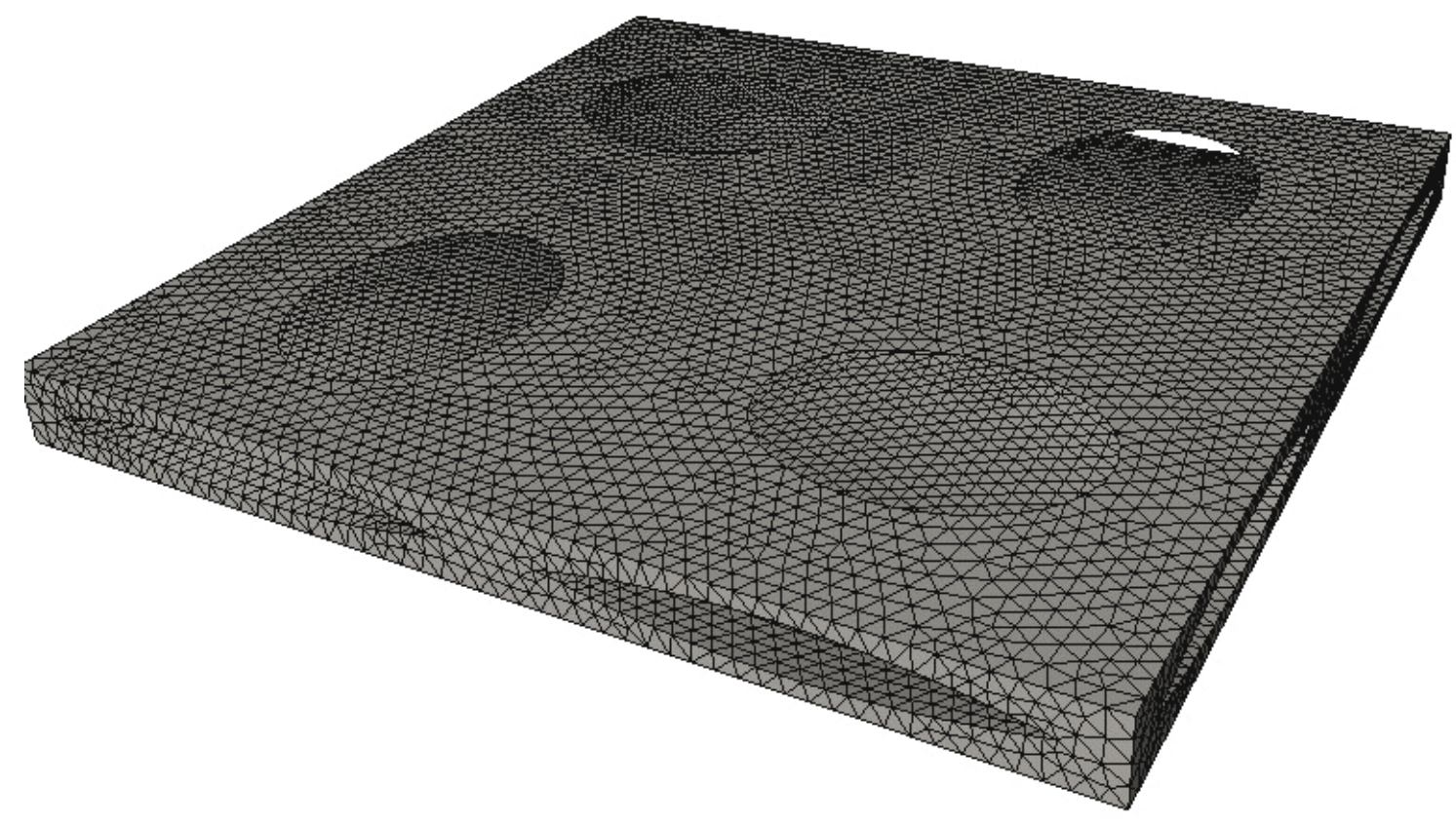

Figure 12. Mesh of the complementary part of a plain weave

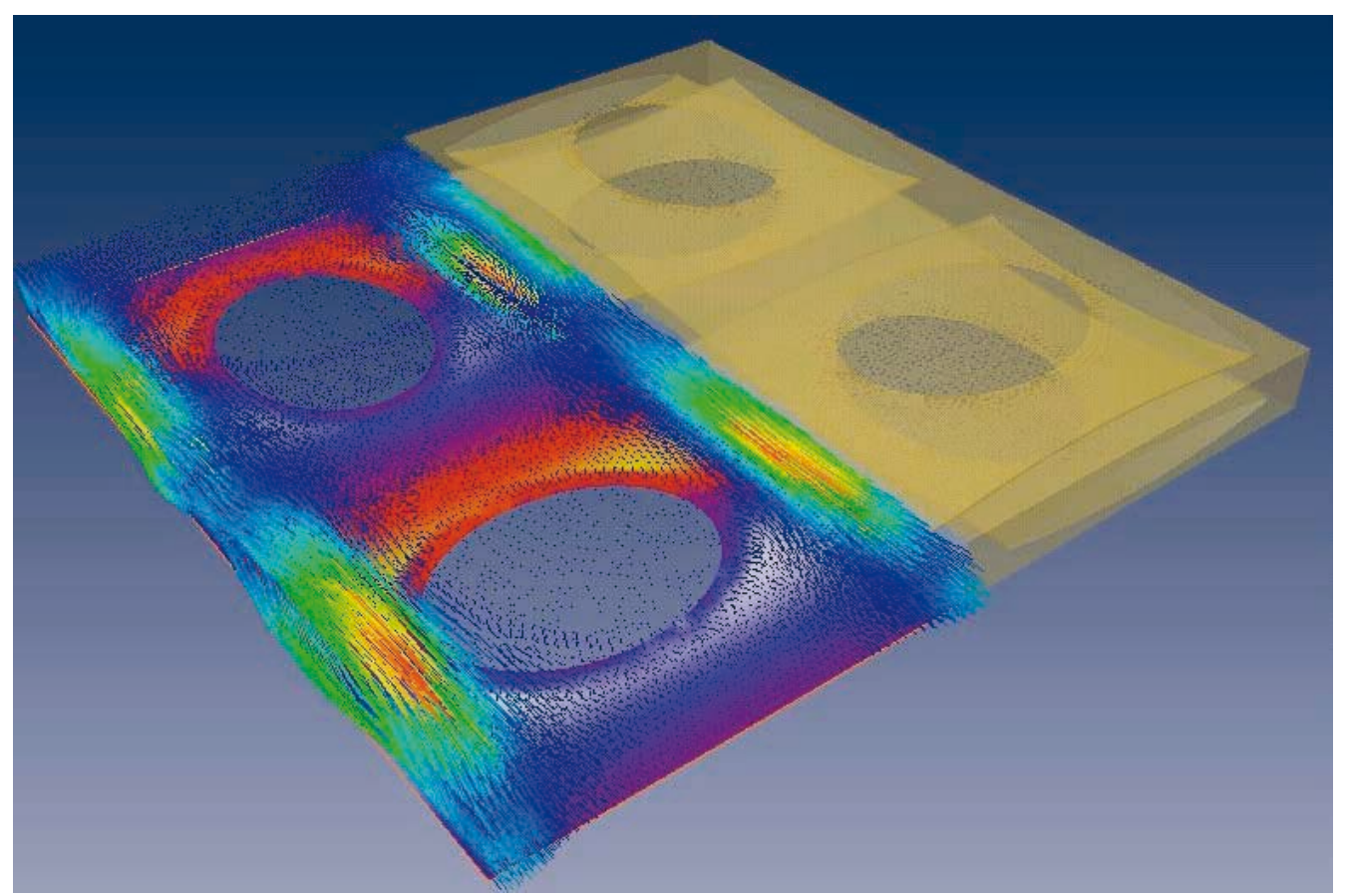

Figure 13. Resin flow in a glass plain weave

\section{Conclusions}

A simple and consistent 3D geometrical model of 2D woven fabrics has been defined, it is adapted to most of the different shapes and weavingit insures no penetrations and no spurious voids in the contact zone between warp and weft 
yarns. It is the first stage of a 3D geometrical meshing preprocessor of the unit woven cells. Using PROEngineer ${ }^{\circledR}$ and Patran ${ }^{\circledR}$, hexahedral meshing of the fabric geometrical model can be obtained. This tool that permits 3D finite element analyses of elementary cells and to determine the mechanical behaviour properties by virtuel tests. It can also be used to simulate the resin flow in the complementary volume of the yarns and in that way calculate te permeability parameters. Future developments will concern more complex types of fabrics, such as $2.5 \mathrm{D}$ or $3 \mathrm{D}$ fabric.

\section{Bibliography}

Boisse P., Gasser A. and Hivet G., "Analyses of fabric behaviour : determination of the biaxial tension-strain surfaces and their use in forming simulations", Composites Part A, 32, 2001, p. 1395-1414.

Buet-Gautier K, Boisse P., "Experimental analysis and modeling of biaxial mechanical behavior of woven composite reinforcements", Experimental Mechanics, 41-3, 2001, p. 260-269.

Bulusu A., Chen J., "Modelling of the unit cell geometry of twill weave fabrics during shear deformation", Proc. of the Fifteenth Technical Conference American Society for Composites, College Station, Texas, USA, 2000, p. 66-75.

Cao H.S. Cheng, Yu T.X., Zhu B., Tao X.M., Lomov S.V., Stoilova T., Verpoest I., Boisse P., Launay J., Hivet G., Liu L., Chen J., Graaf E.F.d., Akkerman R., "A cooperative benchmark effort on testing of woven composites", Proc. $7^{\text {th }}$ ESAFORM Conference, Norway, 2004, p. 305-308.

Carronnier D., Gay D., Approche intégrée du RTM, Revue des composites et des matériaux avancés, 1996, 6, Special issue, Hermès (in French).

Durville D., "Modélisation par éléments finis des propriétés mécaniques de structures textiles: de la fibre au tissu », Revue Européenne des Eléments Finis, Vol. 11, 2002, p. $463-477$

Fournier R., Coupez T., Vincent M., Numerical determination of the permeability of fibre reinforcement for the RTM process, Revue européenne des éléments finis, Vol. 14, No. 67, 2005, p. 803-818

Gasser A., Boisse P. and Hanklar S., "Analysis of the Mechanical Behaviour of Dry Fabric Reinforcements. 3D simulations versus Biaxial Tests", Computational Materials Science, 17, 2000. p. 7-20

Hivet G., Boisse P., "Consistent 3D geometrical model of fabric elementary cell. Application to a meshing preprocessor for 3D finite element analysis", Finite Elements in Analysis and Design, 42, 2005, p. 25-49

Hoes K., Dinescu D., Sol H., Parnas R.S. and Lomov S.V., "Study of nesting induced scatter of permeability values in layered reinforcement fabrics", Composites Part A, 35, 2004, p. $1407-1418$ 
Laine B., Hivet G., Boisse P., Boust F., Lomov S., "Permeability of the Woven Fabrics: A Parametric Study", Proceedings of the $8^{\text {th }}$ Int. Conf. ESAFORM on Material Forming, Cluj-Napoca (Roumanie), Vol. 2, 2005, p. 995-998.

Laine B., Boust F., Boisse P., Fanget A., « Perméabilité des renforts fibreux, écarts modèles numériques-expériences : une tentative de conciliation», special issue «Mise en forme des matériaux composites - AMAC, Revue des composites et Matériaux avancés, Vol. 15, No. 3, 2005, p. 385-400.

Lomov S.V., Gusakov A.V., Huysmans G., Prodomou A., Verpoest I., "Textile geometry preprocessor for meso-mechanical models of woven composites", Composites Science \& Technology, 60, 2000, p. 2083-2095.

Lomov S.V., Truong Chi T., Verpoest I., Peeters T., Roose D., Boisse P., Gasser A., "Mathematical modelling of internal geometry and deformability of woven preforms", International Journal of Forming Processes , Vol. 6 , 2003, p. 413-442.

Kawabata S., Niwa M. and Kawai H., "The finite-deformation theory of plain-weave fabrics. Part I : The biaxial deformation theory", J. Textile Institute, 64, 1973, p. 21-46.

Kuhn J. and Charalambides P., "Modeling of plain weave fabric composite geometry", J. Composite Materials, 33, 1999, p. 188-220.

Peirce F.T., "The geometry of cloth structure”, J. Textile Institute, 28, 1937. p. 45-96.

Prodromou A.G. and Chen J., "On the relationship between shear angle and wrinkling of textile composite preforms", Composites Part A: Applied Science and Manufacturing, 1997, 28, 5, p. 491-503

Robitaille F., Long A.C., Jones I.A., Rudd C.D., "Automatically generated geometric descriptions of textile and composite unit cells", Composites Part A, 34, 2003, p. 303312.

Rudd C.D., Long A.C., Liquid Molding Technologies, ed. Woodhead Publishing Limited, 1997. 